\title{
LAVINIA, DE LA PERIFERIA AL CENTRO. ANÁLISIS DE LAVINLA DE URSULA K. LE GUIN
}

\section{Lavinia, from the periphery to the centre. Analize of Ursula K. Le Guin's Lavinia}

\author{
Patricia Zapata* \\ Universidad Nacional de la Patagonia Austral \\ pzapata@uarg.unpa.edu.ar
}

Palabras clave

Virgilio;

Le Guin;

voz;

periferia;

centro

Keywords

Virgil;

Le Guin;

voice;

periphery;

centre

\section{Resumen}

El trabajo se propone un análisis del personaje de Lavinia basado en la novela homónima de Ursula K. Le Guin. Nuestro recorrido considera el pasaje de la periferia al centro de la escritura. El discurso de Lavinia reflexiona acerca del rol del héroe, acerca del poeta y del poder de los textos. Finalmente, este vínculo entre Eneida de Virgilio, que nos recuerda que el poder asociado con la acción y la palabra pertenece a los hombres, y Le Guin cuya narrativa se focaliza en la experiencia y la voz femenina de la protagonista.

\begin{abstract}
The purpose of this article is to analize the character of Lavinia based on the novel by Ursula K. Le Guin. Our exploration exposes its passage from periphery to the centre of writing. Lavinia's speech reflects about the hero role, about the poet and power of the texts through time. Finally, this link between Virgil's Aeneis who reminds us that the power entailed both action and speech belongs to men and Le Guin whose narrative focuses in feminine experience and the voice of the protagonist.
\end{abstract}




\title{
Lavinia, de la periferia al centro. Análisis de Lavinia de Ursula K. Le Guin
}

\author{
al menos por una vez tendré que romper el silencio y hablar \\ Ursula K. Le Guin
}

La épica ha tenido un anclaje obligado en la representación masculina bajo la figura de un poeta o vate que ostenta el poder de develar las hazañas y el tiempo promisorio del héroe, y del mundo representado en su poesía. En Eneida esta referencia se manifiesta en unos breves versos que señalan la transición de la primera a la segunda parte. Es el momento en el que la voz del poeta expresa su confianza en la creación de un poema mayor porque va a referir nada más y nada menos que a la fundación histórica de Roma:

\footnotetext{
Nunc age, qui reges, Erato, quae tempora rerum, quis Latio antiquo fuerit status $[\ldots]$ expediam et primae revocabo exordia pugnae, Tu vatem, tu, diva, mone. Dicam horrida bella, (...) Maior rerum mihi nascitur ordo maius opus moveo.
}

$$
\text { (Aen. VII, } 37 \text { y ss. })^{1}
$$

Ea, Erato, ahora voy a explicar qué reyes, qué circunstancias de los tiempos, cuál era la situación en el antiguo Lacio, y me remontaré a los mismos comienzos de la lucha.

Tú diosa, tú, aviva el seso del poeta. Voy a hablar de guerras horripilantes, una serie más importante de acontecimientos se abre ante mí, una obra más importante promuevo.

El poeta, consciente de su rol en el imaginario cultural del círculo de Augusto, se configura como garante de una creación que se propone trascender el tiempo y el espacio. Con la escritura asume su importancia y también la responsabilidad en la confluencia de la historia y del mito para narrar el recorrido de su héroe que corona la consolidación del poder de Augusto en el siglo I a.C.

En este contexto, construye la imagen de un personaje femenino como el de Lavinia, hija de Latino, pretendida por muchos hombres del gran Lacio y de toda Ausonia, entre ellos, Turno. En su caracterización la presenta como "iam matura viro, iam plenis nubilis annis" (Aen. VII, v. 53) ("Ya madura para un varón, ya en una edad propicia para el matrimonio").

En relación con su figura, se anuncian presagios vinculados con la llegada de un hombre extranjero y su ejército (VII, vv. 65-66). Su destino está señalado:

\footnotetext{
1. Las citas latinas de Aen. pertenecen a la edición de Les Belles Lettres, París, 1993. La traducción es propia.
} 
Namque fore inlustrem fama fatisque canebant ipsam, sed populo magnum portendere bellum.

(Aen. VII, 79-80)

Vaticinaban que ella sería ilustre por la fama y por el destino pero que llevaría a su pueblo a una gran guerra.

Paradójicamente, Creúsa, referente del mundo que se destruye, Troya, con su profecía le anticipa a Eneas el tiempo feliz que vendrá unido por un reino y una esposa real (II, 783).

Hardie (1998, p. 84) destaca que el propósito de Eneida es el matrimonio estrechamente vinculado con Lavinia a la que asigna un rol pasivo y al mismo tiempo necesario en la constitución del entramado poético y tal como lo observa Cairns (1989, p. 151) es una figura clave en el poema. En definitiva es la figura de la mujer puesta al servicio de un universo hegemónicamente masculino.

Esta característica tal vez ha sido la provocación para que Ursula Le Guin en Lavinia (2008) le diera al personaje homónimo el protagonismo y la voz que cuestiona ese orden a través de una revisión de la condición heroica, de una reflexión del rol del poeta y la función de la tradición a través del tiempo. La misma autora, al recordar el momento de gestación de su novela, señala:

Lavinia empezó a "hablarme" antes de que acabara mi muy lenta lectura de La Eneida. Me refiero a que empecé a pensar en ella: ¿Quién era? ¿Qué opinaba sobre tener que casarse con ese extranjero? ¿Cómo era su vida, la de la hija de un rey en la Edad de Bronce en esa parte de Italia? Ella hizo lo que los personajes de las novelas hacen cuando empiezan a cobrar vida en la mente de uno. Estaba ahí todo el tiempo. (...) En cuanto le pedí a Lavinia que me hablara de sí misma, empezó a hacerlo, con su propia voz, de ahí el uso de la narración en primera persona. Me limité a escuchar y a escribir. (en Comeau, 2010)

En el recorrido intertextual de la épica a la narrativa, el personaje de Lavinia funciona como un enlace entre el mito y la historia; no obstante, Le Guin la distancia de ese lugar típico y le da la libertad para discernir acerca de la escritura, de las grandes epopeyas que escriben los hombres, tema central en su diálogo con "la alta sombra" de Virgilio.

De este modo, en el siglo XXI, a partir de su relectura de Eneida, Le Guin focaliza en las emociones y los pensamientos que le otorgan humanidad a un personaje muchas veces olvidado y relegado a un mero instrumento del destino. Para ello le habilita la voz y la mirada para juzgar el universo creado y condicionado por esa masculinidad. Analizamos aquí la recreación del personaje de Lavinia que se hace visible a través de un discurso que cuestiona los tópicos canónicos de la épica virgiliana y posibilita una reflexión acerca de la situación de la mujer desde el pasado al presente. 


\section{Lavinia entre la tradición y la ruptura del mito}

Tal como lo señala Alicia Ostriker (en De Luce, 1993, p. 305), la mitología es un terreno inhospitalario para una mujer. En esta línea de análisis, De Luce (1993, p. 305) destaca que leemos experiencias de los hombres, las vidas de los hombres en palabras de los hombres y de acuerdo con esta tradición, la mujer del mito reproduce las voces de autores masculinos.

En la actualidad, es relevante considerar la reflexión de Vicente Cristóbal (2015, p. 364) acerca de la crisis del mito a partir de su mutación cuando es sometido a nuevas configuraciones. En este sentido destaca que el ingreso del mito en la literatura es un momento crítico porque tal coyuntura lo somete a una alteración y simultáneamente incorpora el juicio de valor del autor que lo retoma y recrea. Así el estatuto tradicional se convierte en una mirada individual. En estos términos, y en relación con la novela de Ursula K. Le Guin, el mito de Lavinia es objeto de crisis en la medida de su novedosa consideración. En efecto, la voz del poeta es reemplazada por un personaje femenino lo que determina una nueva perspectiva de los hechos.

Como punto de partida, la reescritura de Le Guin caracteriza a Lavinia como "una bella durmiente"(Cristóbal, 2015, p. 75) que esperaba el beso vivificante de la literatura. En esta resurrección, su personaje reclama: "Él no me dejó decir una sola palabra, así que habré de arrebatársela. Me dio una vida larga pero pequeña. Necesito espacio, necesito aire” (p. 14).

En referencia al protagonismo de Lavinia en la novela de Le Guin, nos resulta pertinente la reflexión de Andries Du Toit cuando reseña (2009):

For as the story makes clear, Lavinia is the shaper of events in this story, the one who changes the course of events. It is she that causes the war, it is through her choices that Aeneas comes to settle in Latium, that a new city is founded, that a new dynasty comes into being, a dynasty that leads to nothing less than the founding of Rome, the creation of a new empire, the unfolding of events that lead to this civilization, to us, reading and writing here, in the twenty-first century. (párr. 6) ${ }^{2}$

Sería ingenuo pensar que este juego intertextual con Eneida es un simple ejercicio de escritura. Por el contrario, a través de Lavinia, Le Guin se permite y nos habilita una reflexión y un cuestionamiento a la configuración dominante de una forma de leer y de ver el mundo. Lavinia resume esta visión con respecto a su poeta:

Y, sin embargo, mi papel en todo ello, la vida que me dio en su poema, es tan aburrido -salvo en el momento en que se me prende el cabello-, tan monótono -salvo cuando mis mejillas de doncella enrojecen como el marfil pintado con tinte carmesí tan convencional, que ya no puedo seguir soportándolo. Si he de pervivir siglo tras siglo, al menos por una vez tendré que romper el silencio y hablar. (Le Guin, 2012, p. 14)

2. "Para nosotros la historia es clara, Lavinia es la protagonista de los eventos de este relato, la que cambia el curso de los hechos. Es ella la causa de la guerra, es a través de sus elecciones que Eneas se asienta en el Lacio, que se funda una nueva ciudad, que una nueva dinastía comienza a surgir, un pueblo que lidera nada menos que la fundación de Roma, la creación de un nuevo imperio, un despliegue de hechos que conducen a esta civilización, a nosotros, a la lectura y a la escritura en este siglo veintiuno".

3. A partir de aquí las referencias pertenecen a Ursula Le Guin, Lavinia (2012), traducida por Manuel Mata. 
En clave con el poema épico, Ursula K. Le Guin parte de esa imagen para reconstruir poéticamente el mito de Lavinia quien en el protagonismo de su relato cuestiona la convención no solo de su personaje sino las normas que condicionaron su existencia.

Como ejemplo nos situamos en un diálogo entre Lavinia y la sombra de Virgilio que reconstruye la conflictiva llegada de Eneas al Lacio, el relato subvierte ese mundo épico y desbarata la imagen heroica:

A mí no me ha costado mucho creer en mi condición ficticia, porque, a fin de cuentas, es casi insignificante. Pero para él sería muy difícil. Aunque en este momento esté inactivo, domesticado, sea un hombre satisfecho que, sentado bajo el sol, charla con su esposa, al apasionado, autoritario, ansioso y peligroso héroe de mi poeta le costaría aceptar su contingencia, la nulidad de su voluntad y de su consciencia. La piedad, la fe, la obediencia a lo que, en justicia, se debe hacer, el fas, es el deseo de su corazón. Saber que ha obedecido a un poeta antes que a su consciencia podría angustiarlo..., aunque entendiera, como yo entiendo, que el poeta obedecía a su consciencia y seguía el fas. ¿Por qué debería atribularlo con eso cuando sus preocupaciones son tan grandes y el tiempo de que dispone tan escaso? (p. 137)

\section{Lavinia del silencio a la voz como centro de la escritura}

No es banal la recurrencia de un "yo" que responde a la construcción de una subjetividad que transforma a Lavinia en un sujeto que reflexiona acerca de la escritura y de la función del poeta en su diálogo con el espectro de Virgilio. En el inicio de su recorrido, nos ofrece una visión de su mundo que trasciende su particularidad para representar un colectivo de la imagen femenina:

Mi madre estaba loca, pero yo no. Mi padre era viejo, pero yo era joven. Como la espartana Helena, provoqué una guerra. Ella lo hizo dejando que la tomaran los hombres que la deseaban. Yo, no dejándome dar ni dejándome tomar, sino eligiendo a mi hombre y mi destino. (p. 14-15)

Tal convicción expuesta por el personaje nos llevaría a pensar en una postura feminista extrema y de confrontación con el universo masculino. Sin embargo, adoptar tal solución para comprender el trabajo de Le Guin sería facilista. Su voz narrativa trasciende a través de Lavinia que expresa categóricamente: "No soy la voz femenina que podríais esperar (...). El resentimiento no es lo que me guía el escribir mi relato” (p. 82).

En efecto, su versión de Lavinia se distancia de Medea, de Antígona o de Casandra en el sentido de que es una hija responsable de sus obligaciones, madre y esposa. Lavinia no niega la violencia, la muerte o el dolor, no los evade y busca restaurar un orden a través de sus palabras y acciones.

Así, en diálogo con su creador, Lavinia manifiesta su queja por la marginación a la que este la ha sometido. La reflexión acerca de su silencio se convierte en una idea transversal que construye la imagen de Lavinia: "Sin duda, Turno reconocería en mí el retrato trazado por un poeta de una doncella silenciosa y asustada” (p. 31).

Esta caracterización se traslada al episodio en el que la reina ruega a Turno que evite la guerra que anticipa un final trágico para ambos. Lavinia, testigo de la escena, es un personaje inmovilizado, 
una metonimia que se resume en las lágrimas que en definitiva expresan su resignación ante la imposibilidad de poder cambiar su destino:

Accepit vocem lacrimis Lavinia matris
flagrantes perfusa genas, cui plurimis ignem
subiecit rubor et calefacta per ora cucurrit.

(Aen. XII, 64-66)

Lavinia escuchó la voz de su madre con lágrimas

bañadas sus perfumadas mejillas, en la que puso

un fuego un rubor y corrió por su encendido rostro.

Desde su inicio, ese destino está señalado cuando se le promete al héroe las costas lavinias. De acuerdo con ese contexto, Lavinia está rodeada de figuras masculinas tales como su padre Latino, luego Turno y Eneas. Es parte de un espacio doméstico y de las posesiones de un padre que la destina a un matrimonio con un alcance político:

Sola domum et tantas servabat filia sedes iam matura viro, iam plenis nubilis annis.

(Aen. VII, 52-53)

Sola, una hija cuidaba la casa y las vastas posesiones ya madura para un varón, ya en la edad justa para el casamiento.

Esta imagen de Lavinia es la pieza a la que recurre el poeta para consolidar la fundación del Imperio. No necesita más referencias ni un gran protagonismo en el discurso tradicional de la épica. Raramente aparece comparada con otros personajes y ello ha llevado también a que se la considerara irrelevante. Contrariamente, Cairns (1989, p. 152) destaca su importancia al contextualizar el período de producción y de recepción del poema. Al respecto observa que en la Roma republicana o augustal la clase de una mujer jugaba un importante rol en el grado de libertad y desarrollo. Considera como constante que cualquiera fuera la situación de la mujer, la importancia de la hija soltera estaba por encima de otras condiciones femeninas. Para este autor queda en evidencia que Virgilio le atribuye un potencial político y social por ello el epíteto coniunx.

La situación expuesta desde la tradición es cuestionada por el personaje de Le Guin, quien, en el momento en que su padre la ofrece como esposa a los emisarios de Eneas, sostiene:

Oír que se me prometía como cláusula de un tratado, que se me intercambiaba como una copa o un pedazo de tela, podría parecer el mayor insulto que se le podría lanzar a un espíritu humano. Pero los esclavos y las chicas solteras cuentan con este tipo de insultos, incluso aquellos de nosotros a los que se nos ha concedido la suficiente libertad como para que creamos ser libres. Mi libertad había sido grande y por ello había temido su final. (p. 118)

El discurso de Lavinia revisa los cánones impuestos por la cultura masculina en la épica. Se lucha por intereses económicos, se mata en la guerra y los héroes responden a esa expectativa. Así, 
desde su voz, despoja a Eneas de su investidura heroica y lo transforma en "un carnicero amoral e indiscriminado" (p. 139). La guerra es una condición necesaria para la existencia de los héroes, sin embargo ante la mirada de Lavinia, se configura como un acto absurdo y deshumanizante que está a cargo de los hombres. Ante la llegada inminente de los enemigos, Lavinia le pregunta a la sombra de Virgilio:

${ }_{-}^{-}$Por qué tiene que haber guerra?

${ }_{-¡ O}$ Oh Lavinia, esa es una pregunta de mujer! Porque los hombres son hombres. (p. 102)

Eneas mata como un carnicero, según Lavinia (p. 105) y así son las imágenes que lo muestran en la acción bélica. El personaje de Virgilio no desconoce la crueldad de la guerra, no se refiere al heroísmo y solo tiene una justificación: "así se fundan los imperios". Las descripciones de la guerra son realistas, no se ocultan los muertos ni las derrotas: "La ribera y las tierras estaban cubiertas de cadáveres en más de un kilómetro a la redonda” (p. 166).

El discurso épico que justifica la guerra a partir del vínculo entre nación e ideología es cuestionado por Lavinia al recordar la destrucción y la tristeza que ha dejado en su pueblo:

Aquella tarde, la gente salió de las granjas y de la ciudad y encontró a sus hijos, a sus padres y a sus hermanos muertos en el campo de batalla. Algunos llevaron a sus casas los cadáveres para lavarlos, velarlos y enterrarlos. Otros levantaron piras en el mismo sitio donde habían caído, de modo que aquella noche, todos los campos al norte de Laurentum estaban sembrados de fogatas y el humo oscureció las estrellas. (...) La tristeza flotaba sobre la ciudad, oscura y densa como el humo. (p. 167)

Aun la palabra de un vencedor de Troya, Diomedes, le ve el sinsentido a la guerra: "aunque al final vencimos, ¿cuántos regresamos a casa? Nuestra victoria solo nos proporcionó naufragios, muertes y exilios" (p. 168).

En este escenario bélico, Le Guin le otorga a su personaje el poder de la mirada para observar y juzgar desde su perspectiva femenina las imágenes de la guerra. Lavinia se ha trasladado de la épica a la novela y en este proceso su personaje tiene mayor visión y dominio de situaciones impensadas en el discurso épico. Al respecto, Cristóbal (2015, p. 369) observa que así como Eneas en Eneida es situado en alturas para tener una visión y un control de la situación, de igual modo Lavinia es posicionada en lugares desde donde observa la organización y el desplazamiento para la guerra. Se subvierte la jerarquía heroica si recordamos que Eneas solía tener ese privilegio desde su condición de dux:

Subí corriendo a la torre de vigilancia. (...) Me coloqué sobre el parapeto y desde allí contemplé los campos de instrucción y las tierras situadas al norte de la ciudad, más allá de los tejados y de las murallas. (p. 174)

No sé cuánto tiempo duró. Permanecí allí, aferrada al parapeto de la torre, con Maruna y otras mujeres, como otras mujeres y otros niños que sobre los tejados y sobre las murallas, veían cómo mataban los hombres a los hombres. (p. 176) 
La guerra la impulsan los hombres, descriptos como contradictorios e irracionales. Contrariamente, el personaje de Lavinia se eleva al reasumir su rol religioso entre otras mujeres. Su protagonismo se evidencia al resguardar el lar familiaris durante la guerra. En tal circunstancia, su acción se focaliza en su acción política que se resguarda en la aprobación de su pueblo:

Ya no tenía que ocultarme, aislada de las corrientes del sentir popular. El pueblo me mantenía a flote, me sostenía. Había restaurado mi valor. (...)

Encontré la benevolencia en los ojos de los hombres de las calles y de las mujeres de mi casa. Pronunciaban mi nombre con ternura. Me sentía bienvenida, protegida, Mi hogar volvía a ser mío, aunque estuviera bajo asedio. (p. 173)

Así, progresivamente el protagonismo de Lavinia adquiere un liderazgo que no se sostiene solo por el derecho heredado de un linaje real sino por un reconocimiento que le otorgan las demás mujeres. Su carácter pacífico y organizador constituyen una virtus que se relaciona con los ritos de productividad y no con los rituales guerreros. La religiosidad, expresión de la pietas, opera como una crítica del ethos épico virgiliano (Teodoro Peris, 2019, p. 224). Este concepto está representado también en Eneas cuando le transmite a Ascanio un ideal de gobierno:

-Si vas a gobernar el Lacio después de mí y luego transmitirle el trono a tu hermano Silvio, quiero tener la seguridad que aprenderás a gobernar, no sólo a hacer la guerra, que aprenderás a pedirles consejo a los poderes de la tierra y del cielo, para tu pueblo y para ti, que aprenderás a buscar tu masculinidad en un campo más amplio que el de la batalla. (p. 244)

La consideración de las fuerzas de la naturaleza y la relación espiritual que Lavinia y las demás mujeres establecen con esta se presenta desde una perspectiva distinta respecto a la concepción religiosa dominante en el poema virgiliano. Lo religioso está vinculado con la percepción femenina de la naturaleza desde una espiritualidad en la que no tienen espacio los hombres. Le Guin acentúa esta caracterización al ubicarla como una espectadora privilegiada en ese mundo donde sus actos se vinculan tanto con el plano religioso como con el político en su condición de reina. Así la vemos en el bosque con Silvio:

Al día siguiente, con un sol rojo suspendido sobre las neblinas marinas al oeste, seguimos la estrecha vereda hasta la arboleda de Albunea y llegamos al recinto sagrado. (...) Hacía un año o más que nadie realizaba un sacrificio allí. Los restos de vellón del suelo eran meras hebras ennegrecidas. Cortamos un trozo de tierra cubierta de hierba para el altar y Silvio vació el recipiente de vino como ofrenda mientras yo les rezaba a los antepasados y a los poderes del lugar. (p. 280)

La relación de Lavinia con la religión es un nexo entre el discurso virgiliano y el de Le Guin pero aun así innova (Teodoro Peris, 2019, p. 214) en el episodio donde el rey Latino (Aen. VII, 81) se dispone a escuchar el oráculo familiar al incorporarla como testigo de la escena: 
Se situó junto al altar, donde el fuego aún se alimentaba de la grasa del sacrificio y, con la cabeza cubierta, murmuró las palabras de adoración y humilde petición. Yo me senté sobre el vellón de uno de los corderos y presté atención. Temía y anhelaba oír la voz del abuelo, oír cómo le respondía desde aquellos árboles oscuros y silenciosos. (p. 101)

En esta variación de perspectiva, los dioses son parte de la naturaleza, pero han mutado su poder y no tienen una influencia determinante en la acción de la guerra. Con respecto a Juno, diosa que impulsó la desventura de su héroe, el fantasma de Virgilio adhiere a la postura de Lavinia y reflexiona:

El gran Homero de Grecia dice que es el dios el que enciende el fuego. La joven Lavinia de Italia dice que el fuego es el dios. Esto es suelo italiano. Suelo latino. Lucrecio y tú tenéis razón. Eleva tus plegarias, suplica tus bendiciones y no prestes atención a los mitos extranjeros. Son sólo literatura... Así que olvidémonos de Juno. (p. 80)

Como señalamos al inicio del trabajo, el discurso épico nos muestra una Lavinia rodeada y manejada por los intereses masculinos. Esta subordinación incluye su relación con el poeta que la menospreció y que le dio un papel aburrido (p. 14). Desde este lugar, Lavinia revierte esa posición al convertirse en la narradora de su historia, tiene el poder de la escritura y ello le da la potestad de juzgar lo que ha hecho con ella la tradición:

Sin duda existió alguien con mi nombre, Lavinia, pero podría haber sido tan diferente de la idea que yo misma tengo sobre mí, o de la idea de mi poeta sobre mí, que pensar en ella sólo me confunde. Hasta donde yo sé, fue mi poeta el que me otorgó realidad. Antes de él sólo era la más nebulosa de las figuras, poco más que un nombre en una genealogía. Fue él quien me dio la vida, quien me dio a mí misma, y de este modo me capacitó para recordar mi vida y recordarme a mí. (p.13)

Lavinia recorre su aventura como una heroína moderna que reflexiona a través de la escritura acerca de una existencia carente de certezas y que, por el contrario, está inmersa en una nebulosa:

escribo este relato desde alguna región del inframundo cuya existencia desconocíamos, un lugar ilusorio en el que creemos estar vivos, en el que creemos estar envejeciendo y recordar lo que nos sucedió cuando éramos jóvenes. (p. 15)

La vida se traduce en una búsqueda de transcendencia y es en esta circunstancia en la que establece un vínculo con su poeta, con la poesía cuyo triunfo está en superar y hacer pervivir aquello que nombra. Tal como lo señala: "Sin duda, me iré disolviendo hasta desaparecer y perderme en el olvido, como habría hecho ya hace mucho de no haberme invocado, el poeta” (p. 14).

El viaje con el fantasma de Virgilio es un punto de encuentro entre iguales, los une la poesía, la capacidad de descifrar y dar sentido al mundo a través de la palabra. Lavinia lo ratifica: "no es la muerte lo que nos permite entendernos, sino la poesía” (p. 15). En este aspecto también podemos observar una subversión. Así como reconoce que el poeta le dio existencia, ella a la sombra del poeta que retrata como "un espíritu extraviado, afligido y desgraciado" (p. 53) le ofrece el consuelo y la entidad al 
reconocerlo como un interlocutor en un diálogo desenvuelto y sincero. Ante la inquietud de Lavinia por la llegada de los troyanos, el poeta le da la libertad de acción "Haz lo que debes hacer y sucederá lo que debe suceder. Se echó a reír" (p. 55).

La lectura de Eneida tal como la concibió su autor, nos recuerda que el poder pertenece a los hombres y que este se ejerce con la acción y la palabra; Le Guin, por su parte, se focaliza en la experiencia y la voz femenina de la protagonista que complementa los espacios vacíos que le ha dejado su creador:

- ¿Puedes contarme algo más sobre ese hombre que se acerca?

Reflexionó un momento. A pesar de que estábamos hablando con total desenvoltura y sinceridad, con total confianza, como si los dos fuéramos sombras inofensivas e invulnerables, con toda la eternidad ante nosotros, seguía siendo un hombre que pensaba antes de hablar. (p. 57)

\section{Conclusión}

El recorrido realizado en el personaje de Lavinia de Ursula K. Le Guin expresa la transgresión al orden impuesto por la tradición. Podemos considerar este proceso a partir de un desplazamiento que va de la periferia al centro en el sentido del despliegue que tiene el personaje que evoluciona de un espacio doméstico a un poder visiblemente político mediado por la voz y la escritura.

Su reflexión pone en tela de juicio el sentido del dominio masculino que la ha llevado a un injusto relegamiento. En este sentido, su humanidad se manifiesta en un modo de ver el mundo que expresa la transformación que la lleva de un arquetipo épico a asumir un rol que la convierte en guía de su creador y de su pueblo durante la guerra.

En la versión clásica, Lavinia es recordada por el silencio; en la de Le Guin este personaje no está movilizado solo por los mandatos familiares, sino por los sentimientos que la hacen fuerte pero también vulnerable en una aventura introspectiva que la lleva del pasado al presente. Su voz es una expresión real y tangible de la construcción de la propia historia para evitar el olvido.

\section{Referencias bibliográficas}

Cairns, F. (1989). Lavinia and the lyric tradition. Virgil's Augustan epic. Cambridge, Cambridge University Press.

Cristóbal, V. (2015). Lavinia, de Ursula K. Le Guin, una novela virgiliana. Cuadernos de Filología Clásica. Estudios Latinos, 35 (2), 363-376.

Comeau, P. J. (2010). Entrevista a Ursula Le Guin. Fifth Estate, 382. https://bit.ly/36hUuBk.

De Luce, J. (1993). O for a Thousand Tongues to Sing. A Footnote on Metamorphosis, Silence, and Power. En De Forest, M. (ed.), Woman's Power, man's Game. Essays on Classical Antiquity in Honor of Joy K. King (pp. 305-321). Wauconda, Bolchazy-Carducci Publishers. 
Du Toit, A. (1 de Agosto de 2009). Lavinia's voice (or: the critique of Rome). A subtle Knife. https://bit.ly/3xmyilv.

Hardie, P. (1998). Virgil. The Aeneid. Oxford, Oxford University Press.

Teodoro Peris, J. L. (2019). Deconstrucción y crítica del ethos épico en Lavinia (2008) de Ursula K. Le Guin. Minerva. Revista de Filología Clásica, 32, 211-229.

*Patricia Zapata es Profesora y Licenciada en Letras (IUSC-Adscripto a la UNS). Es profesora adjunta en Lengua y Cultura Latinas I y II en la Unidad Académica de Río Gallegos (Universidad Nacional de la Patagonia Austral). Actualmente, dirige el PI (29/A 475-1) "Historia, mito y política en Eneida y su influencia en la configuración geopolítica del Imperio Romano” (2021-2022).

RECIBIDO: 06/05/2021

ACEPTADO: 08/06/2021 